\title{
Avaliação das condições higiênico-sanitárias em pizzarias na cidade de Marabá, Pará, Brasil
}

\author{
Evaluation of sanitary conditions in pizzerias in the city of Marabá, Pará, Brazil
}

\author{
D. A. Martins ${ }^{1}$; J. L. Carneiro ${ }^{1}$; J. C. Pereira ${ }^{1}$; S. R. Cordovil ${ }^{1}$; B. A. Silva ${ }^{2 *}$ \\ ${ }^{1}$ Graduados do curso de Tecnologia de alimentos/Laboratório de Tecnologia de alimentos/Universidade do Estado \\ do Pará(UEPA). Endereço: Av. Hiléia, s/n-Agrópole do INCRA - Amapá, CEP: 68502-100 - Marabá, PA - Brasil. \\ ${ }^{2}$ Docente do Departamentos de Tecnologia de alimentos - CCNT/ Laboratório de Tecnologia de \\ alimentos/Universidade do Estado do Pará(UEPA) Endereço: Travessa Enéas Pinheiro, 2626, Marco CEP: \\ 66095100 - Belém, PA - Brasil. \\ *bruna_alimentos@yahoo.com.br \\ (Recebido em 08 de abril de 2016; aceito em 05 de maio de 2016)
}

\begin{abstract}
Objetivo do trabalho foi avaliar as condições higiênico-sanitárias de três pizzarias da cidade de MarabáPA. Para avaliação dos estabelecimentos A, B e C foi desenvolvido com base nas RDC no 216 e 275, um check-list composto por 57 perguntas relacionadas aos seguintes itens: I - Edificação, instalações, equipamentos, móveis e utensílios; II - Higienização de instalações, equipamentos, móveis e utensílios; III - Controle integrado de vetores e pragas urbanas; IV - Abastecimento de água; V- Manejo dos resíduos; VI - Manipuladores; VII - Matérias-primas, ingredientes e embalagens. Para a avaliação dos resultados foram utilizados os seguintes critérios: excelente > $91 \%$; bom $\geq 70$ a $90 \%$; regular $\geq 50$ a $69 \%$; ruim $\geq 20$ a $49 \%$ e péssimo $<19 \%$. As pizzarias A, B e C apresentaram os seguintes resultados: item (I) $34 \%, 96 \%$ e $52 \%$; item (II) $40 \%$, $83 \%$ e $29 \%$; item (III) $63 \%, 88 \%$ e $25 \%$; item (IV) $70 \%$, $95 \%$ e $50 \%$; item (V) 67\%, 100\% e 59\%; item (VI) 63\%, $84 \%$ e 36\%; item (VII) 50\%, 93\% e 50\% respectivamente. Conclui-se que dentre a pizzaria $\mathrm{B}$ apresentou os maiores índices de conformidade aos itens analisados e os resultados encontrados nas pizzarias A e C, foram preocupantes, sendo assim, necessário a realização de cursos de boas práticas de fabricação aos manipuladores, para capacita-los conforme as atividades desenvolvidas. Concluiu-se que os estabelecimentos analisados somente um encontra-se em condição higiênico-sanitária adequada, sendo que o comprometimento de todos os envolvidos é uma condição básica para a eficácia na higiene.
\end{abstract}

Palavras-chave: Check list, Pizzaria, Qualidade.

Work objective was to evaluate the sanitary conditions three pizzerias in the city of Maraba-PA. To evaluate the properties A, B and C was developed based on RDC No. 216 and 275, a checklist consists of 57 questions related to the following: I - Construction, facilities, equipment, furniture and fixtures; II Hygiene facilities, equipment, furniture and fixtures; III - Integrated control of vectors and urban pests; IV - Water supply; V- waste management; VI - Brokers; VII - Raw materials, ingredients and packaging. For the evaluation of the results the following criteria were used: Excellent $>91 \%$; Good $\geq 70$ to $90 \%$; regular $\geq 50-69 \%$; bad $\geq 20$ to $49 \%$ and bad $<19 \%$. Pizzerias A, B and C showed the following results: item (I) $34 \%, 96 \%$ and $52 \%$; item (II) $40 \%, 83 \%$ and $29 \%$; Item (III) $63 \%, 88 \%$ and $25 \%$; Item (IV) $70 \%$, $95 \%$ and $50 \%$; Item (V) $67 \%, 100 \%$ and $59 \%$; item (VI) $63 \%, 84 \%$ and $36 \%$; Item (VII) $50 \%, 93 \%$ and $50 \%$ respectively. It is concluded that the pizzeria B had the highest rates of compliance with the items analyzed and the results found in pizzerias A and C were worrying, therefore, necessary to perform good manufacturing practice courses for handlers to enable them as the activities. It was concluded that the establishments analyzed only one is in proper hygienic and sanitary condition, and the commitment of all stakeholders is a basic condition for effective hygiene.

Keywords: Chec klist, Pizzeria, Quality. 


\section{INTRODUÇÃO}

Os alimentos sejam de origem vegetal ou animal, processados ou não, podem ser causadores de diversas doenças aos seres humanos, como as intoxicações e infecções alimentares. A contaminação dos alimentos pode ocorrer por diversas falhas durante o processamento que abrange, desde a recepção das matérias primas até a distribuição dos produtos finais $[1,2,3]$.

As Doenças transmitidas por alimentos (DTAs) são consideradas um problema de saúde pública, e o aumento das DTAs estão relacionados a fatores como o desenvolvimento econômico, a globalização do comércio de alimentos, a intensificação da urbanização, as modificações nos hábitos alimentares dos consumidores, dentre outros [4].

Os casos de DTAs em serviços de alimentação geram perdas tanto para as empresas tais, como pizzarias e restaurantes quanto para os consumidores. Para as empresas, as perdas estão relacionadas ao aspecto financeiro, em decorrência da diminuição da credibilidade e gastos com ações legais. Em relação aos consumidores os prejuízos estão relacionados a saúde, pois alguns contaminantes podem ocasionar danos irreversíveis como a morte do consumidor [5, 6].

Segundo Agência Nacional de Vigilância Sanitária (ANVISA), as boas práticas são regidas pela RDC $\mathrm{n}^{\circ} 216$ de 15 de setembro de 2004, que descrevem os procedimentos necessários para atingir um determinado padrão de identidade e qualidade de um produto ou serviço na área de alimentos, cuja eficácia e efetividade devem ser avaliadas através de inspeção dos estabelecimentos, ajudando a evitar ou reduzir os perigos químicos, físicos e microbiológicos [7].

Partindo-se da premissa de que os alimentos podem ser veículos de transmissão de microrganismos patogênicos e deterioradores, a sua qualidade higiênico-sanitária é obrigatória para garantir a segurança alimentar, que tem sido amplamente estudada e discutida, por profissionais da área de alimentos [8]. Em virtude disto, torna-se necessário a implantação de programas de boas práticas nos estabelecimentos que processam, armazenam e distribuem alimentos, além da conscientização dos proprietários e funcionários, uma vez que os mesmos são os principais responsáveis pelo fornecimento de alimentos seguros. Para garantir a qualidade dos alimentos, também é necessário que os órgãos de fiscalização atuem rigorosamente.

Diante do exposto, o objetivo do trabalho foi avaliar as condições higiênico-sanitárias de três pizzarias da cidade de Marabá, PA.

\section{MATERIAL E MÉTODOS}

Para avaliação das condições higiênico-sanitário foi desenvolvido com base nas Resolução No $^{\circ} 16$ de setembro de 2004 [7] e pela Resolução No 275, de 21 de outubro de 2002 [9], um check-list composto por 57 perguntas relacionadas aos seguintes itens de avaliação.

A lista de verificação check-list aborda os seguintes item: I - Edificação, instalações, equipamentos, móveis e utensílios; II - Higienização de instalações, equipamentos, móveis e utensílios; III - Controle integrado de vetores e pragas urbanas; IV - Abastecimento de água; VManejo dos resíduos; VI - Manipuladores; VII - Matérias-primas, ingredientes e embalagens.

Para a avaliação dos resultados e classificação dos estabelecimentos foram utilizados os seguintes critérios: excelente $>91 \%$; bom $\geq 70-90 \%$; regular $\geq 50-69 \%$; ruim $\geq 20$ a $49 \%$ e péssimo $<19 \%$. Os estabelecimentos escolhidos para este estudo estão situados no Bairro Novo Horizonte da cidade de Marabá-PA, localizados próximos uns dos outros, tendo uma faixa de preços relativamente iguais.

Para preservar a identidade dos estabelecimentos os mesmos foram codificados pelas letras A, B e C. 


\section{RESULTADOS E DISCUSSÃO}

Os resultados referentes aos itens I, II, III, IV, V, VI e VII do check-list aplicado nas pizzarias A, B e C estão apresentados na Tabela 1.

Tabela 1: Resultados dos itens I, II, III, IV, V, VI e VII das pizzarias A, B e C.

\begin{tabular}{lccc}
\hline \multicolumn{1}{c}{ Check-list } & A & B & C \\
\hline Edificação, instalações, móveis e utensílios & $34 \%$ & $96 \%$ & $52 \%$ \\
\hline Higienização de instalações, equipamentos e utensílios & $40 \%$ & $83 \%$ & $29 \%$ \\
\hline Controle integrado de vetores e pragas urbanas & $63 \%$ & $88 \%$ & $25 \%$ \\
\hline Abastecimento de água & $70 \%$ & $95 \%$ & $50 \%$ \\
\hline Manejo dos resíduos & $67 \%$ & $100 \%$ & $59 \%$ \\
\hline Manipuladores & $63 \%$ & $84 \%$ & $36 \%$ \\
\hline Matérias-primas, ingredientes e embalagens & $50 \%$ & $93 \%$ & $50 \%$ \\
\hline
\end{tabular}

Verificou-se que a pizzaria A, apresentou $34 \%$ de conformidade em relação ao item I Edificação, instalações, equipamentos, móveis e utensílios e as pizzarias B e C apresentaram $93 \%$ e $52 \%$, respectivamente. Conforme os resultados obtidos a pizzaria A foi classificada como ruim, $\mathrm{B}$ excelente e $\mathrm{C}$ regular. A classificação ruim da pizzaria $\mathrm{A}$, deve-se ao fato da mesma não apresentar ralos sifonados, paredes, teto e piso não serem de material liso e impermeável, as luminárias não possuíam proteção contra explosão e quedas acidentais e as janelas não eram teladas. Em relação a pizzaria C, as portas não possuíam fechamento automático e os filtros dos equipamentos de climatização não eram higienizados periodicamente.

Vale ressaltar que a ventilação dos estabelecimentos alimentícios deve garantir o conforto térmico e a renovação do ar, além disto, é necessário que o ambiente esteja livre de fungos, gases, fumaça, dentre outros, para não comprometer a qualidade higiênico-sanitária dos alimentos [7].

Os resultados referentes ao item II - Higienização de instalações, equipamentos, móveis e utensílio, a pizzaria A e C foram classificadas como ruins, pois apresentaram $40 \%$ e $29 \%$ respectivamente de conformidade para o item II, e a pizzaria B foi classificada como bom com 83\%. Os níveis de conformidade para os estabelecimentos A e C devem-se ao fato dos equipamentos, móveis e utensílios não serem higienizados corretamente, as caixas de gordura não eram limpas periodicamente, os produtos saneantes não eram identificados e armazenados no local apropriado, não disponibilizavam materiais para assepsia das mãos e os coletores de resíduos não eram dotados de tampa.

Conforme o Controle integrado de vetores e pragas urbanas (item III) apresentado na Tabela 1, a pizzaria A obteve $63 \%$ de conformidade, B $88 \%$ e C $25 \%$, sendo assim, classificadas em regular, bom e ruim, respectivamente. Durante a avaliação do estabelecimento B não foram observados vetores e pragas urbanas, nem animais domésticos na área de processamento e comercialização dos produtos, além disto, foram apresentados os documentos referentes a dedetização do local, fato este não verificado nos estabelecimentos A e C.

Todas as empresas que processam alimentos devem realizar um conjunto de ações eficazes e contínuas de controle de vetores e pragas urbanas, com o objetivo de impedir a atração, abrigo, acesso ou proliferação dos mesmos e se as medidas preventivas adotadas não forem eficazes, o controle químico deverá ser empregado e executado por empresas especializadas, com produtos autorizados pelo Ministério da Saúde [7].

Segundo o item IV - Abastecimento de água), as porcentagens obtidas para os estabelecimentos A, B e C foram $70 \%$ (bom), 95\% (excelente) e 50\% (regular), 
respectivamente. $\mathrm{O}$ estabelecimento $\mathrm{C}$ não realizava a higienização periódica (intervalo máximo de seis meses) dos reservatórios de água e não analisavam a qualidade microbiológica e físicoquímica da água, conforme preconizado pela legislação vigente. A pizzaria $\mathrm{B}$, utilizada água potável, tanto para a lavagem de equipamentos e utensílios, quanto para o processamento dos alimentos e produção de gelo.

Vale ressaltar que a avaliação microbiologia e físico-química da água utilizada por estas empresas é fundamental, pois a água interfere diretamente na qualidade microbiológica dos produtos, sendo assim considerada um meio de contaminação química e microbiológica dos alimentos.

De acordo com o item V - Manejo dos resíduos, a pizzaria A e C obtiveram 67\% e 59\% de conformidade e foram classificadas como regulares e o estabelecimento B obteve $100 \%$, sendo assim classificado como excelente. Observou-se que o estabelecimento $\mathrm{A}$ e $\mathrm{C}$ não possuíam lixeiras identificadas e íntegras de fácil higienização, os resíduos não eram coletados corretamente e estocados em locais distantes da área de processamento e armazenamento dos alimentos.

A RDC $\mathrm{n}^{\circ} 216$ de setembro de 2004, preconiza que os resíduos devem ser acondicionados em lixeiras que permaneçam fechadas até o momento da coleta dos materiais descartados, além disto, a coleta deve ser realizada com frequência para que não haja acúmulo de lixo, o que pode atrair ratos, baratas, moscas e outros insetos ou pragas indesejáveis, além de proporcionar a contaminação do ar com odores desagradáveis.

A Tabela 1, mostra que as pizzarias A, B e C apresentaram $63 \%, 84 \%$ e $36 \%$ de conformidade para o item VI - Manipuladores e foram classificadas como regular, bom e ruim, respectivamente. Verificou-se que no estabelecimento $C$, os manipuladores com lesões e sintomas de enfermidades não eram afastados das atividades, e não possuíam o hábito de higienizar as mãos sempre que necessário, além de utilizarem adornos e esmaltes durante o processamento dos alimentos. Esta prática aumenta os riscos de contaminação química, física e microbiológica aos produtos, e por esse motivo, todos os manipuladores devem retirar anéis, pulseiras, cordões, relógios, dentro outros, antes de entrarem nas áreas destinadas ao preparo dos alimentos. Na pizzaria $C$ também não foi observado cartazes de orientações referentes aos procedimentos higiênico-sanitários e as roupas e objetos pessoais não eram guardados em locais adequados.

As pizzarias A e C apresentaram 50\% (regular) de conformidade e B 93\% (excelente), para o item VII (matérias-primas, ingredientes e embalagens). O estabelecimento A e C não realizavam a inspeção dos produtos adquiridos pelos fornecedores, a recepção de matérias-primas e ingredientes não eram realizados em áreas protegidas e limpas, além de não serem organizados e armazenados em locais adequados como paletes ou prateleiras. Além disto, não verificavam a temperatura das geladeiras e freezers, o que é essencial para o controle da conservação dos alimentos perecíveis e semi-perecíveis.

\section{CONCLUSÃO}

Conclui-se que entre as pizzarias analisadas na cidade de Marabá-PA, a que apresentou maior índice de conformidade aos itens analisados foi o estabelecimento B. Vale ressaltar que os resultados encontrados nas pizzarias A e C são preocupantes, sendo assim, necessário a realização de cursos aos manipuladores, para capacita-los conforme as atividades desenvolvidas, pois a partir da conscientização dos funcionários é possível aumentar o grau de segurança e a confiabilidade dos produtos ofertados aos consumidores, o que diminui os riscos de doenças transmitidas por alimentos. 


\section{REFERÊNCIAS BIBLIOGRÁFICAS}

1. Amson GV, Haracemiv SMC, Masson ML. Levantamento de dados epidemiológicos relativos a ocorrências/ surtos de doenças transmitidas por alimentos (DTAs) no estado do Paraná - Brasil, no período de 1978 a 2000. Revista Ciência Agrotécnica, 2006; 30 (6): 1139-1145.

2. Ávila R, Andrade RB, Machado DRJ, Rabelo RP, Silva, MR. Práticas higiênico-sanitárias na manipulação de alimentos: diagnóstico e intervenção. Com. Ciências Saúde, 2010; 21 (2): 117-124.

3. Tondo, E.C.; Bartz, S. Microbiologia e sistemas de gestão da segurança de alimentos. Porto Alegre: Sulina, 2011, $263 \mathrm{p}$.

4. Vasconcelos, V. H. R. Ensaio sobre a importância do treinamento para manipuladores de alimentos nos serviços de alimentação baseada na RDC N ${ }^{\circ}$ 216/2004. Monografia. Centro de Excelência em TurismoCET. Universidade de Brasília-UNB, 2008.

5. Forsythe SJ. Microbiologia da segurança alimentar. Porto Alegre: Artmed, 2000, 424p.

6. Leite LHM, Waissmann W. Doenças transmitidas por alimentos na população idosa: riscos e prevenção. Revista Ciência Médica, 2006; 15 (6): 525-530.

7. BRASIL. Ministério da Saúde. Agência Nacional de Vigilância Sanitária. Resolução RDC n. 216, de 15 de setembro de 2004. Dispõe sobre o regulamento técnico de boas práticas para serviços de alimentação. Diário Oficial da República Federativa do Brasil, Brasília, DF, 16 set. 2004. p. 1-10.

8. Akutsu RC, Botelho RA, Camargo, EB, Sávio KEO, Araújo WC. Adequação das boas práticas de fabricação em serviços de alimentação. Revista de Nutrição, 2005; 18 (3): 419-427.

9. BRASIL, RDC $\mathrm{n}^{\circ} 275$, de 21 de outubro de 2002. Dispõe sobre o Regulamento Técnico de Procedimentos Operacionais Padronizados aplicados aos Estabelecimentos Produtores/Industrializadores de Alimentos e a Lista de Verificação das Boas Práticas de Fabricação em Estabelecimentos Produtores/Industrializadores de Alimentos. Agencia Nacional de Vigilância Sanitária. 